\title{
Thirty Years of Counting Cancer Cases: The Collective Effort and Efficacy of the National Cancer Database
}

\author{
Cary Jo R. Schlick, MD ${ }^{1}$ and David J. Bentrem, MD, MS ${ }^{1,2}$ \\ ${ }^{1}$ Surgical Outcomes and Quality Improvement Center (SOQIC), Department of Surgery, Feinberg School of Medicine, \\ Northwestern University, Chicago, IL; ${ }^{2}$ Surgery Service, Jesse Brown VA Medical Center, Chicago, IL
}

Our scientific community has mapped the human genome and is currently creating a Human Cell Atlas as a table of contents for every cell type in the human body. ${ }^{1}$ Despite these advances, we still do not know with certainty the exact number of new cancer cases in the US each year, or the treatments each patient receives. Cancer surgeons, both independently and collectively through the American College of Surgeon's Commission on Cancer, have been a driving force for large-scale cancer research efforts for over 100 years. Surgeons helped establish the American Association for Cancer Research (AACR), which was founded by four surgeons in conjunction with five pathologists and two biochemists, as well as the American Cancer Society (ACS). ${ }^{2,3}$

Dating back to the 1920s, Dr. Ernest Codman, an iconoclastic surgeon from Massachusetts General Hospital, meticulously recorded his patient's treatments and outcomes. He recognized the importance of following cancer patients as an early quality improvement endeavor, and thus developed the first cancer registry consisting of bone sarcoma patients. ${ }^{4}$ Shortly thereafter, individual states, beginning with Connecticut, developed statewide cancer registries to record clinical outcomes. ${ }^{5}$

These efforts escalated in the 1980s, at which time cancer surgeons across the country were advocating to advance cancer research through investment in recording cancer outcomes. Around 1987, the late Dr. Gerald Murphy, the national director for the ACS at the time, suggested the Commission on Cancer create a national

(C) Society of Surgical Oncology 2019

First Received: 20 January 2019;

Published Online: 6 March 2019

D. J. Bentrem, MD, MS

e-mail: dbentrem@nm.org assessment of cancer care. ${ }^{6}$ Dr. David Winchester, then medical director of Cancer Programs at the American College of Surgeons, obtained approval from the College for a National Cancer Database (NCDB). After presenting to the board of directors of the ACS in New York City, there was rigorous debate as to whether to support such an endeavor. In the end, the board voted to support the NCDB, thereby establishing a vital partnership and allowing this concept to become a reality. In 1989, the College, through the Commission on Cancer with support from the ACS, established the NCDB.

For reasons of posterity, it is fitting that the NCDB was established in Chicago, the same city where, a century earlier, Walter Shewhart at Western Electric Company first utilized the concept of recording and quantifying various aspects of complex work to improve performance. He used schematic control diagrams to 'separate signal from noise', thereby establishing the field of industrial quality control as a means to decrease variation in manufacturing processes. ${ }^{7}$ The NCDB is maintained today as a quality resource in cancer care, to evaluate treatments and outcomes of patients with cancer. ${ }^{8}$

Previous conventional thinking has been that the NCDB is a hospital-based registry of self-reported cases by Commission on Cancer member institutions, and may not accurately reflect the general US population. In contrast, Surveillance, Epidemiology, and End Results (SEER) data, which is supported by the National Cancer Institute, is an organized, population-based sample of cancer cases designed to assess disease incidence backward over time, and has therefore been seen as the gold standard for cancer studies. ${ }^{9}$ However, as the NCDB sample size has grown for clinical and treatment variables, it has encompassed a larger proportion of the population, and thus the likelihood of bias in well-designed studies has decreased. 
At present, approximately 1500 US hospitals submit their cancer data to the NCDB. The article by Mallin et al. establishes the NCDB as capturing $72 \%$ of the United States Cancer Statistics (USCS) sample, which is increased compared with prior reports. ${ }^{10-12}$ Congress established the National Program of Cancer Registries in 1992 by enacting the Cancer Registries Amendment Act. This act authorized the Centers for Disease Control and Prevention (CDC) to provide funds to States to maintain cancer registries. The USCS is compiled through these state-based cancer registries in 46 states, excluding New Mexico, Iowa, Connecticut, and Hawaii; the SEER database is used to supplement the data for these four states.

In Illinois, cancer cases are collected through mandated reporting by hospitals. The Illinois State Cancer Registry is certified by the North American Association of Central Cancer Registries and has received the gold-standard award for the past 20 years for over $95 \%$ or better case ascertainment. It is probably safe to assume the state registries miss up to $5 \%$ of cases, which are likely from lowerresourced hospitals.

In the report by Mallin et al., Arkansas is the state with the lowest case coverage by the NCDB, with $19.7 \%$ coverage. ${ }^{10}$ In terms of disease site, prostate cancer has the lowest coverage. One factor that could contribute to this finding is that the USCS includes prostate cancer cases from Veterans Affairs (VA) hospitals, while cases from VA hospitals in the NCDB are excluded in the study by Mallin et al. Ninety-seven percent of VA cancers are diagnosed in men, with prostate cancer being the most commonly diagnosed malignancy in this population. ${ }^{13}$ The decision to exclude VA hospitals from the NCDB analysis will thereby affect the prostate cancer ascertainment rate the most.

The report by Mallin et al., establishing the growing US cancer case coverage rate in the NCDB demonstrates the vital importance of this effort. ${ }^{10-12}$ The NCDB is a model of collaboration and collective will on the part of the American College of Surgeons/Commission on Cancer and the ACS. This arduous work needs to continue to document cancer care, recurrence, and disease-specific survival so that as a nation we may continue to work toward answering questions regarding how we treat cancer and to what extent patients benefit from those treatments.

\section{REFERENCES}

1. Regev A, Teichmann S, Lander ES, et al. The human cell Atlas. Elife. 2017;6:e27041.

2. American Association for Cancer Research. History of the AACR. https://www.aacr.org/ABOUTUS/PAGES/AACR-NAR RATIVE-HISTORY.ASPX. Accessed 14 Jan 2019.

3. To Extend Fight on Cancer: Laymen and Physicians Form a Nation-Wide Organization. New York: The New York Times; 1913.

4. Codman EA. The classic: the registry of bone sarcomas as an example of the end-result idea in hospital organization. Clin Orthop Relat Res. 2009;467(11):2766-70.

5. Haenszel W, Gurnen MG. The first fifty years of the Connecticut Tumor Registry: reminiscences and prospects. Yale J Biol Med. 1986;59(5):475-84.

6. Holleb AI. Quality assurance in the care of the patient with cancer. Cancer. 1990;65(11):2419-20.

7. Schlick CJR, Castle JP, Bentrem DJ. Utilizing big data in cancer care. Surg Oncol Clin N Am. 2018;27(4):641-52.

8. Hu QL, Ellis RJ, Ko CY. Databases for surgical health services research: national cancer database. Surgery. 2018;15(40):1-2.

9. Hankey BF, Ries LA, Edwards BK. The surveillance, epidemiology, and end results program: a national resource. Cancer Epidemiol Biomarkers Prev. 1999;8(12):1117-21.

10. Mallin K, BA, Palis B, et al. Incident cases captured in the National Cancer Database compared with those in the U.S. population based Central Cancer Registries in 2012-2014. Ann Surg Oncol. 2018;2018-11-2318.R1.

11. Bilimoria KY, Stewart AK, Winchester DP, et al. The national cancer data base: a powerful initiative to improve cancer care in the United States. Ann Surg Oncol. 2008;15(3):683-60.

12. Lerro CC, Robbins AS, Phillips JL, et al. Comparison of cases captured in the national cancer data base with those in population-based central cancer registries. Ann Surg Oncol. 2013;20(6):1759-65.

13. Zullig LL, Sims KJ, McNeil R, et al. Cancer incidence among patients of the U.S. Veterans Affairs Health Care System: 2010 update. Mil Med. 2017;182(7):e1883-91.

Publisher's Note Springer Nature remains neutral with regard to jurisdictional claims in published maps and institutional affiliations. 